\title{
The energetics of anaerobic muscle metabolism: a reappraisal of older and recent concepts ${ }^{\text {i3 }}$
}

\author{
Pietro Enrico di Prampero a, Guido Ferretti ${ }^{\text {b.* }}$ \\ "Dipartimento di Scienze e Tecnologie Biomediche. Unirersità di Udine. Piazzale Kolhe 4. I-33100 Udine, Italy \\ b Département de Physiologie. Centre Médical Unitersitaire. I rue Michel Sertet. CH-1211 Genère 4, Switzerland
}

Accepted 24 August 1999

\begin{abstract}
This paper discusses under an energetic perspective the recent and older evidence supporting the classical notion that the 'oxygen debt', as originally defined by Margaria et al. (1933) [Am. J. Physiol. 106, 689 714], consists of two major components: the alactic oxygen debt, with a half-time of the order of $30 \mathrm{sec}$, and the lactic oxygen debt, with a much longer half-time, similar to that of lactic acid removal from blood after exercise $(\approx 15 \mathrm{~min})$. In particular, two ensuing concepts are treated, namely (i) the energetic equivalent of blood lactate accumulation in blood, whence the notions of lactic power and lactic capacity, and (ii) the energy sources allowing contraction of the oxygen deficit at the onset of square-wave exercise. The notion of alactic oxygen deficit is rediscussed on the basis of recent evidence in humans. The analogies between lactate accumulation during supramaximal exercise and during exercise transients are discussed under an energetic perspective. (C) 1999 Elsevier Science B.V. All rights reserved.
\end{abstract}

Keywords: Exercise, energetics; Lactic acid, removal; Lactic acid, energy equivalent: Mammals, humans; Muscle, skeletal, lactic acid: Oxygen, debt

\section{Introduction}

The aim of this paper is to review briefly about 40 years of a main chapter of the history of the energetics of muscular exercise, namely that of the

Dedicated to Professor Paolo Cerretelli on the occasion of his retirement from a chair of physiology at the University of Geneva, Switzerland.

*Corresponding author. Tel.: + 41-22-702-5363; fax: +41$22-702-5402$.

E-mail address: guido.ferretti@medecine.unige.ch $(\mathrm{G}$. Ferretti) anaerobic energy sources. It seems fair to say from the outset that we will not try to present a comprehensive review of the matters at stake. We will rather focus on facts and theories generated by the 'School of Margaria' from the early sixties onwards, not only because this paper is dedicated to Paolo Cerretelli, who was and still is one of the leaders among Rodolfo Margaria's heirs, but also and especially because we are convinced that the concepts created by the School of Margaria, and summarized below, can provide a solid background and a good starting point for many as yet unanswered questions.

0034-5687 99 S - see front matter 1999 Elsevier Science B.V. All rights reserved.

PII: S0034-5687(99)00083-3 
In 1933, a paper entitled 'The possible mechanism of contracting and paying the oxygen debt and the role of lactic acid in muscular contraction', was published in the American Journal of Physiology (Margaria et al., 1933). This paper, indeed a seminal one, introduced the concept of 'alactic oxygen debt', and for this very reason initiated a revolution in the physiology of muscular exercise. The 'phosphagens' had been recently identified (Eggleton and Eggleton, 1927; Fiske and Subbarow, 1927; Lohmann, 1928), and a number of ensuing observations on isolated muscle contraction was casting a shadow over Hill and Meyerhof's theory of the energetics of muscle contraction (Hill, 1932; for a review see Needham, 1971). According to this theory, for which Hill and Meyerhof were awarded the Nobel Prize for Medicine or Physiology in 1923, oxidation of glycogen to lactic acid is the main energy source for muscular contraction, whereas oxygen is consumed for oxidising a fraction of the accumulated lactic acid, so yielding the energy for the resynthesis to glycogen of the remaining fraction (Hill, 1924). Margaria et al. (1933), by means of a mathematical analysis of the oxygen consumption curve after heavy exercise in man, demonstrated that a substantial fraction of the oxygen debt payment is independent of lactic acid removal from blood. As a consequence, they subdivided the overall oxygen debt in two major components: the alactic oxygen debt, with a shorter time constant $\tau$ (half-time, $t_{1.2}=\tau \ln 2 \approx 30 \mathrm{sec}$ ), and the lactic oxygen debt, with a much longer $t_{12}$, similar to that of lactic acid removal from blood after exercise $(\approx 15 \mathrm{~min}$ ).

These findings generated a brilliant refutation of Hill and Meyerhof's theory, representing a major step forward on the way to our present understanding of the energetics of muscle contraction. Margaria et al. (1933) had studied the kinetics of the oxygen debt payment. The time had come of challenging Margaria's concept of oxygen debt by studying the way it was incurred at the onset of exercise. Apart from the isolated pioneering work of Henry (1951) on exercise transients, this task was essentially undertaken in the early sixties by a group of scientists in Milano, among whom Cerretelli played a major role, under the intellectual leadership of Rodolfo Margaria.
This led to the creation of two basic concepts in the energetics of muscular exercise: (i) the energetic equivalent of blood lactate accumulation in blood. whence the notions of lactic power and lactic capacity, and (ii) the obligatory fraction of oxygen deficit at the onset of exercise. These concepts are discussed, under a historical perspective, in the present paper. The paper is therefore divided in two sections, the first devoted to an analysis of the anaerobic lactic energy sources, the second to the energetics of the oxygen deficit and debt.

\section{The anaerobic energy sources}

\subsection{The energy equiralent of lactic acid formation}

Margaria et al. (1963a) determined the energy cost of running at various speeds and inclines of the terrain, allowing an estimate of the corresponding metabolic power requirements. So the Milano group set out to determine the rate of lactate accumulation in blood at speeds and inclines requiring a metabolic power larger than that corresponding to the subjects' maximal oxygen consumption (Margaria et al., 1963b). Each constant supramaximal speed trial was subdivided into several bouts of increasing duration, until volitional exhaustion. After each bout, the subject was asked to rest and the lactic acid concentration in blood measured throughout the recovery period. Assuming that (i) the peak concentration of lactic acid, attained between the 5th and the 8th min of recovery, is equal throughout the body fluids, and (ii) the water fractions of the blood and of the whole body are 0.8 and 0.6 respectively, it was possible to estimate the amount of lactic acid produced per $\mathrm{kg}$ of body mass. This made it possible to demonstrate, as believed at those times, that the rate at which lactic acid is produced (in $\mathrm{g} \mathrm{kg}^{-1} \mathrm{~min}^{-1}$ ) (actually accumulated, and on average, as we will see below) increases linearly with the corresponding metabolic power (in kcal $\mathrm{kg}^{-1} \mathrm{~min}^{-1}$ ) (Fig. 1). The intercept on the $x$-axis of this line was considered indicative of the metabolic power below 
which no net production of lactic acid occurs: indeed this intercept corresponded to the power at which the plateau defining the subject's maximal oxygen consumption was attained. The slope of the line was taken as a measure of the amount of energy released in vivo by the production of $1 \mathrm{~g}$ of lactic acid: it amounted to $222 \mathrm{cal} \mathrm{g}^{-1}(84 \mathrm{~kJ}$ $\mathrm{mol}^{-1}$ ). This original result was essentially confirmed by further data from the same school on humans (Margaria et al., 1971, 1972), running dogs (Cerretelli et al., 1964), and isolated-perfused dog gastrocnemii (Cerretelli et al., 1969).

In spite of the consistency of the results, the numerous assumptions underlying the above conclusions stirred a heated debate, in part because some of them were either implicit or definitely unsound, in part because of preconceived, if not altogether wrong, ideas on the energetic significance of lactic acid production. This state of affairs was most unfortunate, because it precluded a widespread practical use of the "energy equivalent of lactate formation in vivo', thus in the end hindering the progress of our knowledge in the field. Indeed we maintain that, as often pointed out ever since, the above calculated energy equivalent, albeit with some cautions and less emphasis, is an extremely useful practical tool for estimating the whole body energy expenditure during supramaximal efforts (for a review see di Prampero, 1981). The last statement is developed in the next paragraphs, where we will first enumerate and discuss the several assumptions underlying this concept, and then report recent and older evidence in its support.

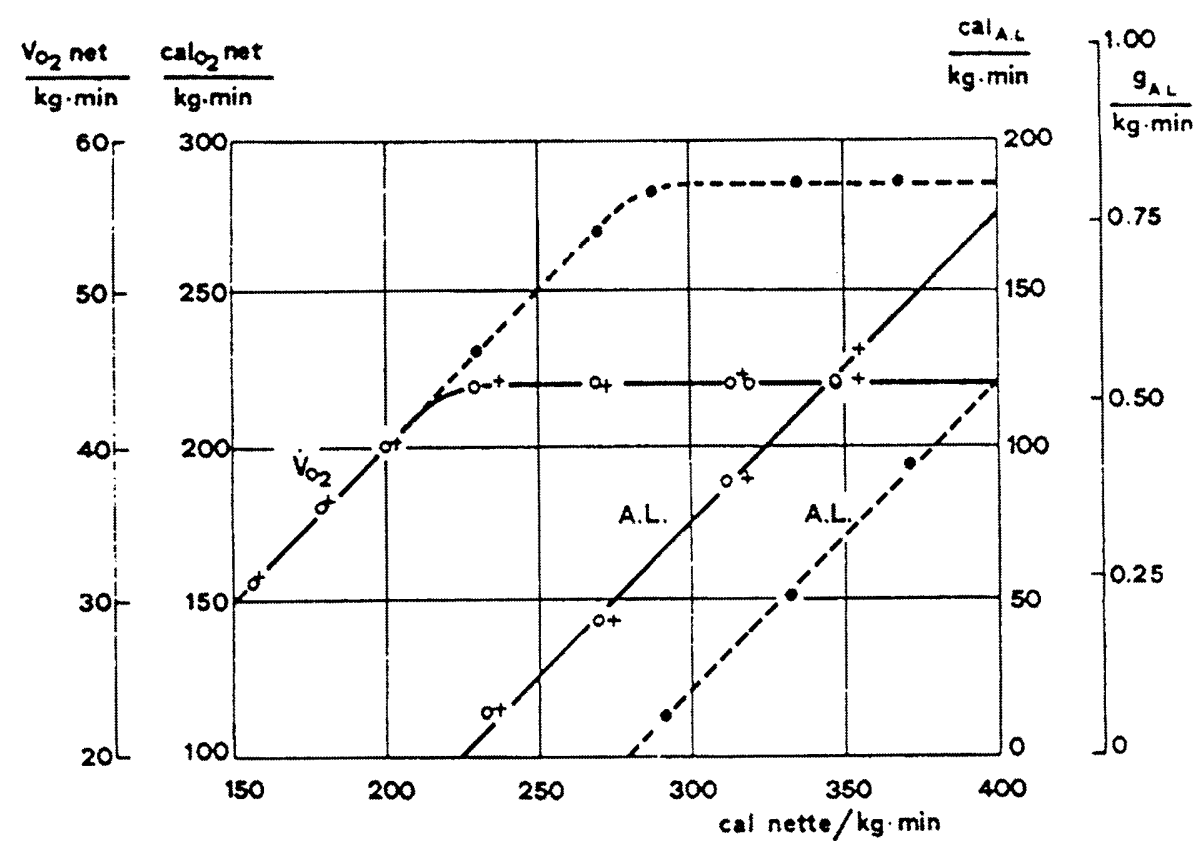

Fig. 1. Increase of lactate in the body in $\mathrm{g} \mathrm{kg}^{1} \mathrm{~min}{ }^{1}$ (right ordinate). and net steady-state $\mathrm{O}_{2}$ consumption per unit of body weight (left ordinate), as a function of the intensity of exercise expressed in cal $\mathrm{kg}{ }^{1} \mathrm{~min}^{\prime \prime}{ }^{1}$. Non-athletes. full line: athlete. broken line. The full line for lactate crosses the abscissa at $220 \mathrm{cal} \mathrm{kg}{ }^{1} \mathrm{~min}^{1}$, about the same value at which the corresponding $\mathrm{O}_{2}$ consumption line reaches its maximum. Below this level, no lactate is produced and the work is carried out aerobically. The lactate line for athletes is displaced to the right. indicating a higher capacity for aerobic work and a higher maximal oxygen consumption. The slope of the two lactate lines is the same and indicates an energy 'production' of about $222 \mathrm{cal} g$ ' $1 \mathrm{of}$ lactate formed. Assuming this value is correct. lactate can be expressed in calories instead of grams. on a scale also reported on the right ordinate. From Margaria et al. (1963b). 

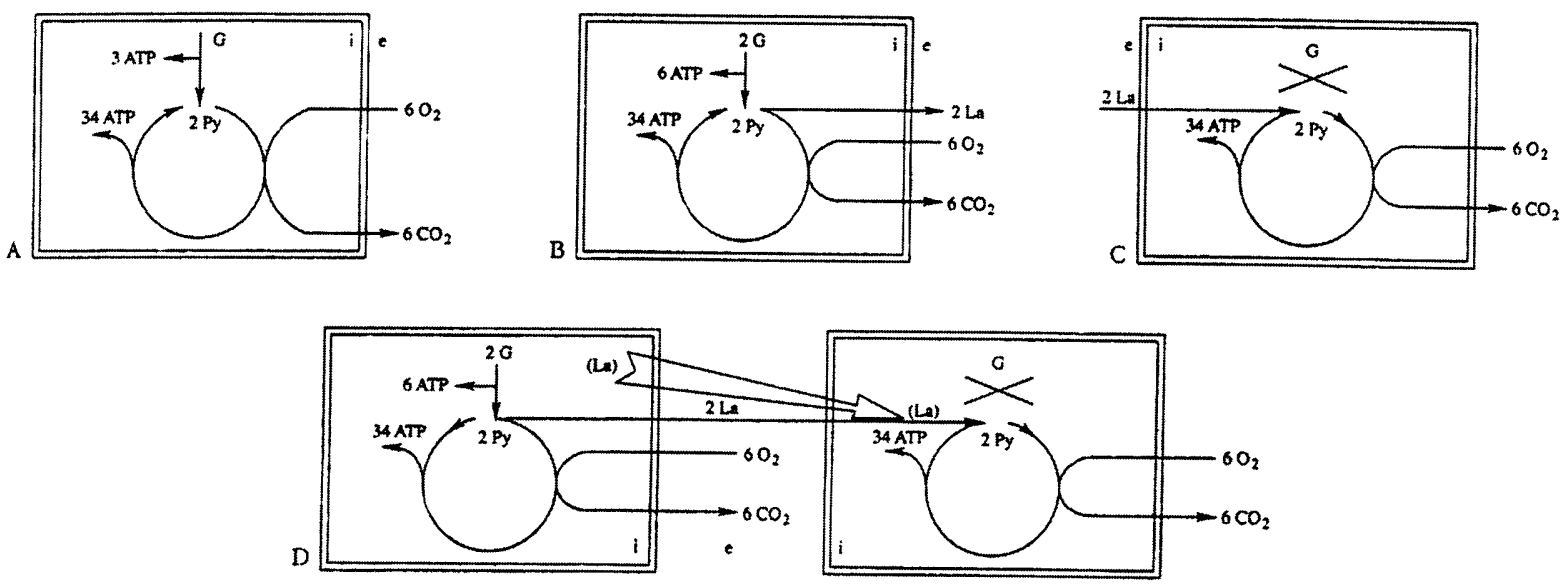

Fig. 2. (A) Muscle fibre in aerobic conditions. The pyruvate (Py) formed from glycogen (G) is fully oxidised to $\mathrm{CO}$, and water. Fach glycogen unit utilised (162 g of glycogen) yields $3 \mathrm{~mol}$ of $A T P$ in the initial phase of the process and 34 mol of ATP in the Krebs cycle. The $\mathrm{PO}_{2}$ ratio amounts then to $(34+3) 6=6.17$. (B) Muscle fibre in hypoaerobic conditions. The amount of pyruvate formed is greater than what can be oxidised in the Krebs cycle. The excess pyruvate is anaerobically transformed into lactate. The $\mathrm{P} \mathrm{O}_{2}$ ratio is higher than in standard aerobic conditions: $(34+6) 6=6.67$. (C) Muscle fibe in hyperaerobic conditions. The fibre lakes up lactate from extra-cellular space and transforms it into pyruvate without breaking glycogen down. The so formed pyruvate can enter the Krebs cycle. The $\mathrm{PO}_{2}$ ratio is lower than in standard alerobic conditions: $346=5.67$. (D) Muscle fibres in unevenly acrobic conditions. The coupling of "hypoaerobic" and "hyperacrobic" fibres leads to a fully aerobic system. The P O, ratio is equal to that for standard aerobic conditions $(34+34+6) 12=6.17$. As indicated by the arrow. the lactate concentration is highest in the "hypoacrobic" fibre, intermediate in the extra-cellular fluid. and lowest in the coupled "hyperaerobic" fibre. It is noteworthy that this representation bears an analogy with Brooks' concept of the 'lactate shuttle" (Brooks. 1985). i. intra-cellular space: e. extra-cellular space. From di Prampero et ill. (1998).

\subsection{The energetic significance of lactic acid production}

The lactic acid concentration in the body fluids reflects the balance between lactate production and removal. The latter takes place in several organs and tissues, such as the liver, the kidney, the brain, the heart, as well as skeletal muscle. and can lead to either lactate oxidation to $\mathrm{CO}$, and water (Brooks et al., 1999), or to glycogen resynthesis. During severe exercise, glycogen resynthesis is severely depressed, if not altogether abolished, so that lactate removal is due exclusively, or very nearly so, to its oxidation, the first step of which is the reversible transformation of lactate to pyruvate. It is obvious that lactate oxidation, exactly as pyruvate removal into the Krebs cycle, requires oxygen consumption with the same stoichiometric coefficient (moles of substrate per moles of oxygen). As a consequence, when lactate production equals lactate removal, so that the lactate concentration in body fluids stays constant, the rate of oxygen consumption is an overall measure of the whole body energy expenditure, regardless of the magnitude of lactate production and removal and of the absolute lactate concentration. This is what occurs during light aerobic exercise. On the contrary, during intense excrcise, when the lactate concentration in the body fluids keeps increasing. the whole body energy turnover is larger than the oxygen consumption by an amount that is proportional to the net rate of lactate accumulation.

These general considerations are detailed in Fig. 2, in which a number of schematic working hypotheses for lactate production and removal are presented at the level of muscle fibres (di Prampero et al.. 1998): (i) an "evenly aerobic" condition, in which each fibre utilises the pyruvate that it produces, so that no change in lactate concentration occurs as compared to rest; (ii) a 'hypoaerobic' condition, in which active fibres produce more pyruvate than can be oxidised in the Krebs cycle, so that lactate concentration keeps increas- 
ing steadily; (iii) a 'hyperaerobic' condition. in which the active fibres take up and oxidise lactate from the extracellular space in addition to or instead of that produced by themselves. so that lactate concentration keeps decreasing steadily: (iv) an "unevenly aerobic" condition wherein the lactate produced in excess by hypoaerobic fibres is taken up and oxidised by by hyperaerobic fibres nearby, so that, after an initial rise necessary to prime the system. lactate concentration remains stable at a higher level than the resting. It should also be pointed out that this state of affairs is dependent on, and facilitated by, the existence of a lactate transporter (Juel. 1997). The four hypotheses detailed in Fig. 2, once translated to the whole body level, are conceptual analogues of light aerobic exercise. supramaximal exercise. recovery following supramaximal exercise, and intense aerobic exercise (power above $50 \%$ of that corresponding to the maximal oxygen consumption).

This general picture is conceptually identical to that underlying the so called 'lactate shuttle' (Brooks, 1985), which will not be discussed further in this paper. However. an immediate corollary of the above line of reasoning is that the energetic significance of lactate depends on the rate at which its concentration changes in the body fluids. and not to its absolute concentration. As a consequence, the widely used representation of the blood lactate concentration as a function of the exercise intensity cannot and should not be interpreted to mean that, whenever blood lactate concentration exceeds a given threshold (e.g. 4 $\mathrm{mM}$ ). the energy requirement of the exercise is met in part by anaerobic lactic energy sources. Indeed, this widely used representation only implies that. during a certain period of the exercise. usually in its early phase. before the attainment of a steady state in oxygen consumption. a certain amount of energy has been derived from anaerobic lactic energy sources, whence the increase of blood lactate concentration (early lactate, as defined by Cerretelli et al., 1979, see below). It also follows that a continuous anaerobic lactic contribution to the energy requirement can be demonstrated only if the lactate concentration keeps increasing during the exercise.
The results presented in Fig. 1 are not inherently contradictory with the current notion whereby blood lactate concentration is plotted as a function of the exercise intensity. Indeed. they describe different facets of the "lactate" world. The latter is a static picture. reporting lactate concentration at a given point in time. regardless of the preceding events: the former (Fig. I) is a dynamic picture reporting the rate of increase of lactate concentration during the exercise period in which the $O$, consumption has attained a constant. and in that very instance maximal. value.

\subsection{The distrihution of lactate}

The amount of lactate 'produced' per $\mathrm{kg}$ of body mass (Margaria et al. 1963b) was calculated assuming that the peak blood lactate concentration after exercise. attained between the 5 th and 8 th min of recovery. was a measure of the equilibrium lactate concentration throughout the body water. This was also assumed to be equal in the different tissues. regardless of their intra-versus extra-cellular water fractions. The latter, however. is not the case, since lactate anions at equilibrium are preferentially located in the extra-cellular phase (Roos, 1975), so that the amount of lactate per $\mathrm{kg}$ of body mass cannot be easily calculated without knowing the lactate concentrations in intra- and extra-cellular water. together with the corresponding fractions. In addition, Margaria et al. (1963b) did not consider that a certain amount of lactate is inevitably removed during the first five minutes of recovery, before the attainment of the peak blood lactate concentration. Therefore. this is necessarily less than it would be. were lactate diffusion and mixing instantaneous. It follows that Margaria et al. (1963b) performed a rather crude estimate of lactic acid production from peak blood lactate concentration. This statement. however. by no means implies rejection of the concept of the energetic significance of blood lactate accumulation.

If we assume that: (i) the peak blood lactate concentration is the result of an equilibrium condition. which is independent of the actual lactate concentration in extra- and intra-cellular fluids: and (ii) the rates of lactate disappearance in the 
various body fluid compartments have the same time constants, then the kinetics of lactate disappearance from blood should be appropriately described by a monoexponential. This is indeed the case (Margaria et al., 1933; Åstrand, 1960; Margaria et al., 1963b; Hermansen and Stensvold, 1972: di Prampero et al., 1978a,b), the half-time of this monoexponential being: (i) of about 15 min for a resting recovery: (ii) faster if light aerobic exercise is performed during recovery (Gisolfi et al.. 1966); and (iii) independent of the absolute peak blood lactate concentration, at least in the range between 4 and $16 \mathrm{mM}$ (di Prampero et al., 1978a.b). As a consequence, provided that the conditions of recovery are standardised: (i) the peak blood lactate concentration during recovery is, and cannot but be, directly proportional to the overall amount of lactate accumulated in $1 \mathrm{~kg}$ of body mass during the preceding supramaximal exercise; and thus (ii) the rate of lactate accumulation in blood, as calculated from the ratio of the peak blood lactate concentration to the duration of the preceding exercise, is, and cannot but be, directly proportional to the rate of lactate accumulation in $1 \mathrm{~kg}$ of body mass. And this is so, even if it is very difficult, if not altogether impossible, to calculate or measure the last.

In other terms, there is no need of determining the rate of lactate accumulation per $\mathrm{kg}$ of body mass to get information on the energy released by anaterobic lactic metabolism. It would be enough to calculate the reciprocal of the slope of the line, that relates the measured rate of lactic acid increase in blood $\left(\Delta[\mathrm{L} \hat{a}]_{\mathrm{b}} \Delta \mathrm{t}^{-1}\right)$ to the known metabolic power required to perform the corresponding exercises $\left(\Delta \mathrm{E} \Delta \mathrm{t}^{-1}\right)$. This parameter. which is from here on defined $\beta=\left(\Delta \mathrm{E} \Delta \mathrm{t}^{-1}\right)$ $\left(\Delta[\mathrm{L} \hat{a}]_{h} \Delta \mathrm{t}^{\prime}\right)^{-1}=\Delta \mathrm{E} \Delta[\mathrm{La}]_{\mathrm{b}}{ }^{\prime}$, is indeed the coefficient yielding the amount of energy per unit of body mass released by the accumulation of $1 \mathrm{mM}$ of lactate in blood. From the data of Margaria et al. (1963b), $\beta$ turns out to be $3.3 \mathrm{ml} \mathrm{O}_{2} \mathrm{~kg}{ }^{-1}$ $\mathrm{mM}^{-1}$, which means that any $1 \mathrm{mM}$ increase in blood lactate concentration is equivalent to the energy released by the consumption of $3.3 \mathrm{ml} \mathrm{O}_{2}$ per $\mathrm{kg}$ of body mass. This is an empirical energy equivalent, determined without the need of any assumption as to the effective distribution of lac- tate. It can be safely applied as such, provided the experimental conditions are those described and discussed above.

\subsection{The energetics of supramaximal exercise}

During supramaximal exercise, the oxygen consumption may attain its maximal value within say 20-30 sec. After this initial time, we can reasonably assume that no energetic contribution from anaerobic alactic energy sources (Lohmann reaction) subsists. So the energy release per unit of time after the initial period is the sum of two terms, the first referring to aerobic, the second to anaerobic lactic, energy productions, as follows:

$\mathrm{dEdt}=\left(\mathrm{dVO}_{2} \mathrm{dt}\right)_{\mathrm{max}_{\mathrm{x}}}+\beta\left(\mathrm{d}[\mathrm{La}]_{\mathrm{b}} \mathrm{dt}\right)$

where $\mathrm{dE} / \mathrm{dt}$ is the overall metabolic power, $\left(\mathrm{dVO}_{2} \mathrm{dt}\right)_{\text {max }}$ is the maximal aerobic power, $\beta$ is the energy equivalent of lactate accumulation in blood, and $\left(\mathrm{d}[\mathrm{La}]_{\mathrm{h}} \mathrm{dt}\right)$ the rate of lactate accumulation in blood. If $\mathrm{dE} / \mathrm{dt}$ is in $\mathrm{ml} \mathrm{O}_{2} \min ^{-1} \mathrm{~kg}^{-1}$ and $\left(\mathrm{d}[\mathrm{La}]_{\mathrm{h}} \mathrm{dt}\right)$ in $\mathrm{mM}$ min ${ }^{-1}$, then $\beta$ is in $\mathrm{ml} \mathrm{O}_{2}$ min ${ }^{1} \mathrm{mM}{ }^{1}$ (3.3 according to Margaria et al., 1963b). If we express $\mathrm{dE} / \mathrm{dt}$ relative to $(\mathrm{dVO}$ dt) max. $_{\text {. }}$ Eq. (1) becomes:

$\frac{\mathrm{dE} d t}{\left(\mathrm{dVO}_{2} \mathrm{dt}\right)_{\max }}=1+\frac{\beta\left(\mathrm{d}[\mathrm{La}]_{\mathrm{h}} \mathrm{dt}\right)}{\left.(\mathrm{dVO})_{2} \mathrm{dt}\right)_{\max }}$

Eq. (2) allows a comparison of subjects differing in maximal aerobic power, and therefore working at different supramaximal exercise intensities with different exercise modes. From the data of Margaria et al. (1971) during treadmill running and of Pendergast et al. (1977) during swimming, it was possible to calculate $\beta$ from Eq. (2) for the two exercise modes at stake. The results are shown in Fig. 3, where $\mathrm{dE}$ dt is plotted as a function of $\mathrm{d}[\mathrm{La}]_{\mathrm{b}} / \mathrm{dt}$, both expressed relative to the maximal oxygen consumption, for running and swimming. The two regression lines have similar slopes, indicating that the energy equivalent of blood lactate accumulation for the two exercise modes is the same $\left(3.0\right.$ and $2.7 \mathrm{ml} \mathrm{O}_{2} \mathrm{~kg}^{-1} \mathrm{mM}^{-1}$, for running and swimming respectively, to be compared to the figure of $3.3 \mathrm{ml} \mathrm{O}_{2} \mathrm{~kg}^{-1} \mathrm{mM}^{-1}$ discussed above). More recently, Capelli and di Prampero (1995) measured $\mathrm{d}[\mathrm{La}]_{\mathrm{b}} / \mathrm{dt}$ during supramaximal track 
cycling, in a condition in which the overall metabolic power was known. This allowed application of Eq. (2) for the computation of $\beta$, which resulted equal to that calculated for running and swimming.

The striking similarity of these values, independent of subjects, type of exercise, intensity of exercise, and muscles involved, reinforces the view that $\beta$ is indeed the energy equivalent of blood lactate accumulation, and supports its general validity. Clearly enough, $\beta$ is not the energetic equivalent of lactate formation in the working muscles and does not yield any direct information on the stoichiometric relation between lactate formation and ATP resynthesis. It is nevertheless a

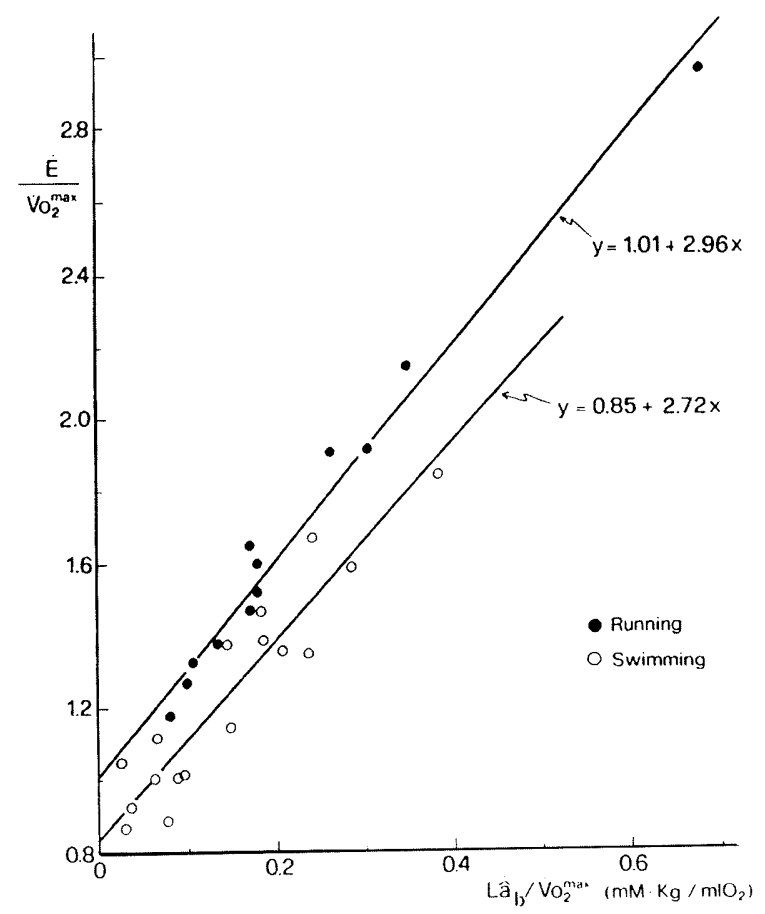

Fig. 3. The overall rate of energy expenditure $(\mathrm{dE} \mathrm{dt})$ is plotted as a function of the rate of lactic acid accumulation in blood $\left(\mathrm{d}[\mathrm{La}]_{\mathrm{h}} \mathrm{dt}\right)$ in running (full dots, data from Margaria et al., 1971) and swimming (open dots, data from di Prampero et al.. 1978b). The comparison of different subjects is made possible by expressing both parameters as ratios to the subjects" maximal oxygen consumption. The regression lines are: $y=1.01+2.96 x(r=0.99)$, and $y=0.85+2.72 x(r=0.94)$. for running and swimming, respectively. The slope of these lines corresponds to the energy equivalent of blood lactate accumulation. Modified after di Prampero (1981). very useful quantity allowing us to determine the energy release in the body whenever the blood lactate concentration increases by a given amount.

\subsection{The maximal lactic power}

Since $d[L a ̂]_{h}$ dt increases linearly with increasing the exercise intensity, it may be expected that it attains a maximum when the energy release from anaerobic lactic metabolism requires exploitation of the glycolytic potential at its greatest extent. That this is indeed the case was demonstrated, again in the sixties, by members of the School of Margaria (including Paolo Cerretelli) in an elegant series of experiments in which subjects ran on a treadmill at $18 \mathrm{~km} \mathrm{~h}^{1}$ at slopes up to $25 \%$, thus performing exercises requiring a metabolic power larger than twice the maximal aerobic power (Margaria et al.. 1964). The results showed that: (i) d[Lâ $]_{b}$ dt attains a constant maximal value which does not increase by further increasing the exercise intensity; and (ii) the time after which $\mathrm{d}[\mathrm{L} \hat{\mathrm{a}}]_{\mathrm{b}} \mathrm{dt}$ starts increasing is shorter the higher the exercise intensity (Fig. 4). Margaria et al. (1964) argued that the energy sources for the time that precedes the increase in $\mathrm{d}[\mathrm{L} \hat{a}]_{\mathrm{b}} \mathrm{dt}$ were anaerobic alactic, namely the net utilisation oh high energy phosphates, particularly phosphocreatine. because of the contraction of the alactic oxygen deficit and because the intensity of exercise was much larger than the maximal aerobic power.

Knowledge of $\beta$, calculated as described above, allowed an estimate of the metabolic power equivalent of the measured maximal rate of lactate accumulation in blood, or maximal lactic power: this amounted to some $75 \mathrm{ml} \mathrm{O}_{2} \mathrm{~kg}^{-1} \mathrm{~min}^{-1}$. i.e. about 1.5 times the subjects' maximal aerobic power. It was higher in power athletes (Hermansen, 1971). and reduced after altitude acclimatization (Grassi et al., 1995).

\subsection{The maximal lactic capacity}

The above data can also be used to draw an overall energy balance of very strenuous exercise in humans. From the (known) total energy requirement of the exercise, the (measured) amount 


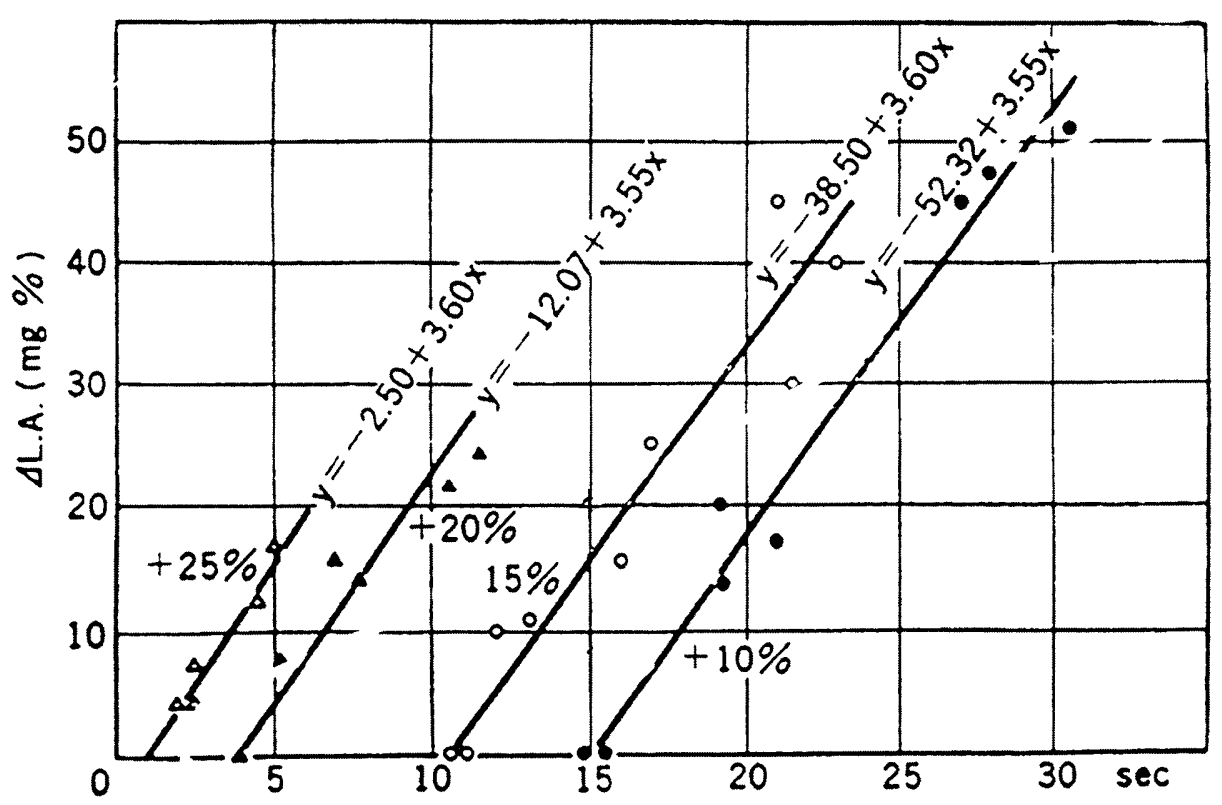

Fig. 4. Increase of lactic acid in blood (in $\mathrm{mg}$ per $100 \mathrm{ml}$ ) as a function of exercise duration (sec). The four lines refer to four work loads, and were obtained by changing the incline on the treadmill from 10 to $25 \%$ at the constant speed of $18 \mathrm{~km} \mathrm{~h} \quad 1$. The slope indicates the rate at which lactic acid is accumulated in blood. Since it is unchanged by increasing the power output (see regression equations on the Fig.). it corresponds to the maximal rate of energy release by blood lactate accumulation. or maximal lactic power. From Margaria et al. (1964).

of lactate accumulated in blood after exhaustion, the (calculated) value of $\beta$, the (measured) subjects' maximal aerobic power, and from the knowledge of the time constant of the $\mathrm{O}_{2}$ consumption kinetics that sets the alactic $\mathrm{O}_{2}$ deficit (23.3 sec, Binzoni et al., 1992), it is possible to calculate the amount of energy that can be derived from the full utilisation of anaerobic lactic energy stores, or maximal lactic capacity. This ranges, for continuous exercise, between 45 and $55 \mathrm{ml} \mathrm{kg}-1$. corresponding to a blood lactate accumulation of about $14-17 \mathrm{mM}$. It varies with the active muscle mass, is higher in power athletes than in non-athletic subjects, can be twice as big after intermittent exercise (Osnes and Hermansen. 1972), and is decreased after altitude acclimatization (see, e.g. Cerretelli and Binzoni, 1990).

Lactate accumulation in muscle is obviously associated with a simultaneous increase in $\mathrm{H}^{+}$ concentration. Thus, the limits to maximal lactic capacity are likely imposed by the maximal $\mathrm{H}$ concentration that can be attained in the working muscles. before inhibition of glycolysis. This in turn depends on the buffer characteristics of muscle fibres and blood, and on the rate at which lactate can be removed from muscles. This, however, may not be the case in altitude acclimatized subjects, in whom an increase in buffer power through bicarbonate administration failed to increase the maximal lactic capacity (Kayser et al., 1994).

\subsection{The P La ratio}

The energy equivalent of lactate accumulation in blood is an epiphenomenon indicating the amount of energy released by anaerobic energy sources for resynthesizing ATP, the hydrolysis of which actually provides the energy for contraction. The knowledge of the amount of ATP resynthesised from the accumulation of $1 \mathrm{~mol}$ of lactate in the working muscles, or $\mathrm{P} / \mathrm{La}$ ratio, is therefore of primary importance. 
In this context, Eq. (1) can be rewritten as follows:

$\left.\mathrm{dATP} d \mathrm{dt}=\mathrm{a}_{(\mathrm{dVO}} / \mathrm{dt}\right)_{\max }+\mathrm{c} \beta\left(\mathrm{d}[\mathrm{La}]_{\mathrm{b}} \mathrm{dt}\right)$

where $\mathrm{dATP} / \mathrm{dt}$ is the rate of ATP resynthesis, $\mathrm{a}$ is the $\mathrm{PO}$, ratio (moles of phosphate resynthesised at the expense of the consumption of $1 \mathrm{~mol}$ of $\mathrm{O}_{2}$ ), and $\mathrm{c}$ is a constant relating blood lactate concentration to the amount of lactate produced $\left([\mathrm{L} \hat{\mathrm{a}}]_{\mathrm{m}}\right)$. Merging constants in Eq. (3) yields:

$\mathrm{dATP} d t=\mathrm{a}\left(\mathrm{dVO}_{2} \mathrm{dt}\right)_{\max }+\mathrm{b}\left(\mathrm{d}[\mathrm{Lâ}]_{\mathrm{m}} / \mathrm{dt}\right)$

where $b(=c \beta)$ is the $P$ La ratio. Computation of the $\mathrm{P} / \mathrm{La}$ ratio from the measurement of blood lactate accumulation in humans is impossible because we do not know the value taken by constant c. It can be calculated, however, from the data determined in isolated dog gastrocnemius muscle stimulated supramaximally with blood flow occluded (di Prampero et al.. 1978a,b).

Under these conditions, the released energy derive essentially from (i) depletion of high energy

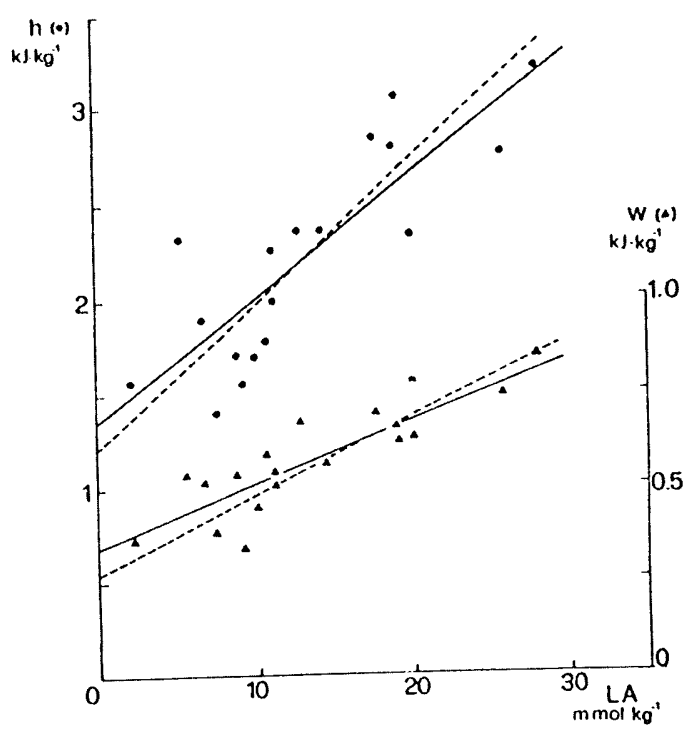

Fig. 5. Enthalpy change (H, kJ kg ', left ordinate, dots) and work output (w, kJ kg ', right ordinate, triangles) as a function of lactic acid formed (LA. mmol kg ') during supramaximal stimulation of isolate perfused dog gastrocnemius in anoxia. The slopes indicate the energy relcased by and the work performed by a unit of lactic acid formed during contraction. From di Prampero et al. (1978a). phosphates, (ii) lactic acid accumulation. plus a minor, negligible amount from muscle $\mathrm{O}_{2}$ stores. Since the high energy phosphate concentration is constant at rest. and it decreases down to almost zero after exhaustive supramaximal stimulation (Cerretelli et al., 1969), the energy supplied by phosphate depletion in the transition from rest to stimulation can be considered constant. This implies that the total standard enthalpy $(\mathrm{H}$, work plus heat) change under those conditions is equal to:

$\mathrm{H}=\mathrm{H}_{\mathrm{al}}+\Delta \mathrm{H}_{\mathrm{L}_{\mathrm{i} \mathrm{i}}}[\mathrm{L} \hat{\mathrm{a}}]_{\mathrm{n}}$

where $H_{a l}$ is the enthalpy change due to high energy phosphates, $\Delta \mathrm{H}_{\mathrm{Li}}$ is the molar enthalpy change due to lactic acid formation from glycogen, and $[\mathrm{La}]_{\mathrm{m}}$ is the overall amount of lactate produced. The relation between $\mathrm{H}$ and $[\mathrm{La}]_{\mathrm{m}}$ was established by di Prampero et al. (1978a), and is reported in Fig. 5. Its slope, equal to $\Delta \mathrm{H}_{\mathrm{l}: \mathrm{i}}$, is 76

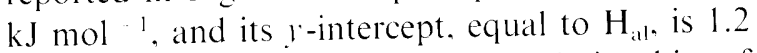
$\mathrm{kJ} \mathrm{kg}^{-1}$. Furthermore, also the relationship of mechanical work output to lactic acid formation was found to be linear (Fig. 5, right ordinate), its slope being a measure of the work done per mole of lactate accumulated $\left(20 \mathrm{~kJ} \mathrm{~mol}^{-1}\right)$. The $\mathrm{P} / \mathrm{La}$ ratio can now be calculated as the ratio of this last value to the work done per mole of phosphate split. Since the latter ranges from 16 to $19 \mathrm{~kJ}$ mol $^{-1}$ (Piiper et al.. 1969; Cerretelli et al., 1972; Ferretti et al.. 1987: Cerretelli and di Prampero, 1988), the $\mathrm{P}$ La ratio in vivo turns out equal to $1.25-1.05 \mathrm{~mol}$ of phosphate per mole of lactate formed, which is less than, but not far from, the value of 1.5 predicted from stoichiometry. If this is so, the enthalpy change of phosphate hydrolysis would range between 60 and $72 \mathrm{~kJ} \mathrm{~mol}^{-1}$, which is remarkably higher than the value of $46 \mathrm{~kJ}$ mol ${ }^{1}$ measured for ATP splitting, or of 50 that can be calculated assuming a $\mathrm{P} / \mathrm{La}$ ratio equal to that in vitro.

\section{Energetics of the oxygen deficit}

At the onset and offset of square wave aerobic exercise, the $\mathrm{O}_{2}$ uptake attains a steady level only after 3-4 min. It follows that the amount of $\mathrm{O}_{2}$ 
that enters the body per unit of time before the attainment of the steady state is less than at the steady state. Since the ATP requirement is constant from the very beginning of the exercise, the rate of $\mathrm{O}_{2}$ uptake during the initial phase is less than stoichiometrically required for fully aerobic ATP resynthesis. It necessarily follows that a fraction of the energy required for ATP resynthesis is derived from other sources than $\mathrm{O}_{2}$ uptake from the lungs. The opposite occurs during recovery.

The increase in $\mathrm{O}_{2}$ uptake during light aerobic exercise is. on first approximation, described by:

$(\mathrm{dVO} / \mathrm{dt})_{\mathrm{s}}-(\mathrm{dVO} / \mathrm{dt})_{1}=(\mathrm{dVO} / \mathrm{dt})_{\mathrm{s}} \mathrm{e}^{-\mathrm{t} \tau}$

where subscripts 's' and ' $t$ ' mean at the steady state and at a given time t, respectively, and where the time constant $\tau$ is about $40 \mathrm{sec}$. Rearranging equation (6):

$\left(\mathrm{dVO}_{2} \mathrm{dt}\right)_{1}=\left(\mathrm{dVO}_{2} \mathrm{dt}\right)_{\mathrm{s}}\left(1-\mathrm{e}^{-1 \tau}\right)$

In the recovery at the end of exercise Eq. (7) becomes:

$\left(\mathrm{dVO}_{2} d t\right)_{t}=(\mathrm{dVO}, \mathrm{dt})_{\mathrm{s}} \mathrm{e}^{-1 \mathrm{t}}$

It follows that the missing oxygen. defined as $\mathrm{O}_{2}$ def, or the extra oxygen during recovery $\left(\mathrm{O}_{2}\right.$ debt $)$, is the time integral of Eqs. (6) and (8):

$\left.\mathrm{O}_{2} \mathrm{def}=\int\left(\mathrm{dVO} \mathrm{O}_{2} \mathrm{dt}\right)_{\mathrm{s}} \mathrm{e}^{-1 \mathrm{t}}\right) \mathrm{dt}=\left(\mathrm{dVO} \mathrm{O}_{2} \mathrm{dt}\right)_{\mathrm{s}} \mathrm{t}$

\subsection{The energy sources for the oxygen deficit}

The energy sources implicated in the construction of the $\mathrm{O}_{2}$ def are essentially three: a reduction in the volume of $\mathrm{O}_{2}$ stores $\left(\mathrm{VO}_{2}\right.$ st), high energy phosphates (phosphocreatine) breakdown $\left(\mathrm{PCrO}_{2}\right)$ and early lactate formation $\left(\mathrm{eLaO}_{2}\right)$. The $\mathrm{O}_{2}$ def is the sum of these three terms, expressed in $\mathrm{O}_{2}$ equivalents. Since lactate removal from blood during recovery is a relatively slow process (see above), only $\mathrm{VO}_{2}$ st and $\mathrm{PCrO}_{2}$ participate in the $\mathrm{O}_{2}$ debt, i.e. what Margaria et al. (1933) called the fast or alactic component of the oxygen debt payment.

This state of things implies that, if we let one of the components of $\mathrm{O}_{2}$ def vary, the two others remaining constant, the $\mathrm{O}_{2}$ def should change ac- cordingly and predictably. Paolo Cerretelli was in the group which firstly operated along this line: in the gastrocnemius plantaris dog preparation, lactate formation at the onset of exercise is negligible, which should lead to a faster $\mathrm{O}_{2}$ uptake kinetics and smaller $\mathrm{O}_{2}$ def than in humans: Piiper et al. (1968) found that this was indeed the case. Thus, in that condition, the energy equivalent to the $\mathrm{O}_{2}$ def was entirely derived, or very nearly so, from phosphocreatine breakdown. whence the notion that the $\mathrm{O}_{2}$ debt was mainly due to phosphocreatine resynthesis. In addition, di Prampero and Margaria (1968) showed that the $\mathrm{PO}_{2}$ ratio, as calculated from the ratio of the amount of phosphate broken down or resynthesised at the onset offset of exercise to the $\mathrm{O}_{2}$ def $\mathrm{O}_{2}$ debt, is close to the canonical value of 6.17 .

That paper prompted a series of experiments in humans, in which $\mathrm{VO}_{2}$ st was manipulated, and $\mathrm{O}_{2}$ def found to change as predicted. A few examples are discussed herein. $\mathrm{VO}_{2}$ st during steady state exercise is smaller the higher the exercise intensity, essentially because of the decrease in mixed venous blood oxygen saturation, so that its contribution to $\mathrm{O}_{2}$ def ought to become predictably smaller in transition from light to heavier work than in transition from rest to either work level: and indeed the $\mathrm{O}_{2}$ uptake kinetics was found to be faster in the former case (di Prampero et al.. 1970). Analogously, in acute normobaric hypoxia, in which $\mathrm{VO}_{2}$ st is decreased, the $\mathrm{O}_{2}$ def was found to be accordingly smaller (di Prampero et al., 1983).

As far as eLaO2 is concerned, Cerretelli et al. (1979) found that $\tau$ was directly proportional to the lactate accumulated in blood during the exercise transient (early lactate), as follows:

$\tau=\lambda[\mathrm{La}]_{\mathrm{b}}+\mathrm{b}$

where $[\mathrm{La}]_{b}$ is the early lactate and $\lambda$ is a constant indicating how much $\tau$ increases per unit increase of lactate in blood during the exercise transient. The constant $\lambda$ is an inverse function of $\left(\mathrm{dVO}_{2}\right.$ dt)s, and from the data of Cerretelli et al. (1979) turns out equal to 7.8 and $12.1 \mathrm{sec} \mathrm{mM}^{-1}$, at $\left(\mathrm{dVO}_{2} \mathrm{dt}\right)_{\mathrm{s}}$ values of 1.5 and $1.0 \mathrm{~L} \mathrm{~min}^{-1}$ (mechanical powers of 125 and $75 \mathrm{~W}$ ), respectively. These values allow computation of the $\mathrm{O}_{2}$ def in- 
crease (in $\mathrm{ml} \mathrm{O}, \mathrm{kg}^{-1}$ ) per unit increase in [La] (in $\mathrm{mM}$ ), which is nothing but the energy equivalent of blood lactate accumulation. This last turns out equal to 2.79 and $2.89 \mathrm{ml} \mathrm{kg}^{-1} \mathrm{mM}^{-1}$ for the 125 and $75 \mathrm{~W}$ power, respectively, two values astonishingly close to those reported above $(2.7$ $3.3 \mathrm{ml} \mathrm{kg}^{-1} \mathrm{mM}^{-1}$ ).

This set of data strongly support the hypothesis that the oxygen deficit results from the simultaneous contribution of three energy sources: oxygen stores, phosphocreatine breakdown. and early lactate accumulation.

\subsection{The net alactic orrgen deficit}

In conditions in which no early lactate accumulation takes place, and no changes in $\mathrm{O}_{2}$ stores occur, the energy released for the contraction of the oxygen deficit comes exclusively from high energy phosphate hydrolysis. If this is so. the time constant $\tau$ of the kinetics of $\mathrm{O}_{2}$ uptake at exercise onset becomes equal to that of phosphocreatine breakdown, as the rates of ATP splitting and ATP resynthesis are equal and the ATP resynthesis from phosphocreatine starts immediately at the exercise onset. Indeed the time constant of phosphocreatine breakdown dictates the fastest possible $\mathrm{O}_{2}$ uptake kinetics. This time constant was measured in humans by nuclear magnetic resonance spectroscopy and found to be $23.4 \mathrm{sec}$, independent of the work load (Binzoni et al.. 1992). This value is practically equal to that for $\tau$. as determined on isolated perfused aerobic dog gastrocnemius (Piiper et al., 1968). A direct consequence of this state of affairs is that the change in muscle phosphocreatine concentration during the transition is directly proportional to the oxygen deficit. This implies a negative linear relationship between phosphocreatine concentration and steady state $\mathrm{O}_{2}$ uptake, as actually found (di Prampero and Margaria, 1968; Piiper et al., 1968; Binzoni et al., 1992).

The contraction of a net alactic oxygen deficit is unavoidable at exercise onset. This is because the key enzymes of glycolysis need to be activated for priming the aerobic metabolism, and their activation is likely mediated by the very initial breakdown of high energy phosphates. The necessity of contracting the net alactic oxygen deficit supports the concept generated in the school of Margaria that the slow increase of $\mathrm{O}_{2}$ uptake at the onset of square wave exercise has a metabolic origin. whereas it constitutes a strong evidence against the alternative concept that the oxygen deficit is imposed by the delay of the respiratory and circulatory system.

\subsection{The kinetics of oxygen consumption during supramaximal exercise}

For exercise intensities exceeding the maximal oxygen consumption. the kinetics of $\mathrm{O}_{2}$ uptake is described by an equation formally similar to that applying for aerobic exercise. In that case. however, the $\mathrm{O}_{2}$ uptake tends toward a steady state at the overall energy requirement of the exercise $\left[\left(\mathrm{dVO}_{2} \mathrm{dt}\right)_{1}\right]$ :

$\left(\mathrm{dVO}_{2} \mathrm{dt}\right)_{1}-\left(\mathrm{dVO}_{2} \mathrm{dt}\right)_{1}=\left(\mathrm{dVO}_{2} \mathrm{dt}\right)_{1} \mathrm{e}^{t^{\mathrm{\tau}}}$

where $\left(\mathrm{d} V \mathrm{O}_{2} \mathrm{dt}\right)_{\mathrm{r}}$ corresponds to the steady state $\mathrm{O}$, uptake that would be attained, were it possible to carry out the exercise under purely aerobic conditions. Obviously enough, this tentative steady state is never reached, as the increase in $\mathrm{O}_{2}$ uptake comes to an end when the maximal $\mathrm{O}_{2}$ uptake is achieved. So. for supramaximal exercise intensities, the maximal $\mathrm{O}_{2}$ uptake is achieved in a time which is shorter the higher the exercise intensity, as experimentally found (Craig. 1972).

In agreement with these observations, at the end of supramaximal exercise. $\mathrm{O}_{2}$ uptake stays at its maximal level for several seconds, because the decrease in $\mathrm{O}_{2}$ uptake ideally starts from $\left(\mathrm{dVO}_{2}\right.$ $\mathrm{dt}_{\mathrm{r}}$, so it is only after the virtual $\left(\mathrm{dVO}_{2} \mathrm{dt}\right)_{1}$, has attained the subject's maximal $\mathrm{O}_{2}$ uptake that the actual $\left(\mathrm{dVO}_{2} \mathrm{dt}\right)_{1}$ starts decreasing. Of course, the time at which the virtual and the actual $\left(\mathrm{dVO}_{2}\right.$ $\mathrm{dt}$ ), in recovery become equal is longer the higher the exercise intensity (di Prampero et al.. 1973).

\section{Conclusions}

The present analysis of the energy release from anaerobic metabolism during supramaximal exercise and during exercise transients provides a re- 
markable body of evidence in support to the notion originally developed by Margaria et al. (1933) that the lactic and alactic oxygen debts. as they were called. provide all the energy required for exercise performance that cannot be released by aerobic metabolism. We hope to have been able to convince a reader that, as far as the anaerobic lactic metabolism is concerned. the amount of energy that it releases can be casily assessed from measurements of the rate at which blood lactic acid changes during exercise.

The historical paper by Margaria et al. (1933). although outdated for several aspects. still defines the cultural context in which the study of the energetics of muscular exercise is carried out nowadays, particularly by his successors. It is a pleasure for us to note the important role played by Paolo Cerretelli in the development of our knowledge in the field since the sixties. This acknowledgement is for us the best way of honouring him on the occasion for which this paper has been written.

\section{References}

Astrand. I.. 1960. Aerobic work capacity in men and women with special reference to age. Acta Physiol. Scand. Suppl. 169, 1960.

Bimzoni, T.. Ferretti. G.. Schenker. K.. Cerretelli. P.. 1992. Phosphocreatine hydrolysis by "P-NMR at the onset of constant-load exercise in humans. J. Appl. Physiol. 73. 16441649

Brooks. G.A.. 1985. The lactate shutle during exercise and recovery. Med. Sci. Sports Exerc. 18. 360 368.

Brooks. G.A., Dubouchaud. H.. Brown. M.. Sicurello. J.P.. But\%. C.E. 1999. Role of mitochondrial lactate dehydrogenase and lactate oxidation in the intracellular lactate shutthe. Proc. Natl. Acad. Sci. USA 96. $1129 \quad 1134$

Capelli. C.. di Prampero. P.E. 1995. Blood lactate aceumulation in exercising humans. Biochim. Clin. 19. 541542.

Cerretelli. P.. Piiper. J.. Mangili. F.. Ricei. B.. 1964. Acrobic and anacrobic metabolism in exercising dogs. J. Appl. Physiol. 19. 29 32.

Cerretelli. P.. di Prampero. P.F.. Piiper, J.. 1969. Energy balance of anaerobic work in the dog gastrocnemius muscle. Am. J. Physiol. 217. 581585.

Cerretelli. P.. di Prampero. P.E.. Ambrosoli. ( .. 1972. High energy phosphate resynthesis from anaerobic glycolysis in frog gastrocnemius muscle. Am. J. Physiol. 222, 102] 1026 .
Cerretelli. P.. Pendergast. D.R.. Paganelli. W.C.. Rennic. D.W. . 1979). Effects of specific muscle training on $V_{0}-0$ on response and early blood lactate. J. Appl. Physiol. 47. 761769 .

Cerretelli. P. di Prampero. P.E.. 1988. High energy phosphate utilization for work production and tension maintenance in frog musck. Pllüg. Arch. 412. 270 276.

Cerretelli. P.. Binzoni. T.. 1990. Musculal exercise at high altitude. V1. The energetic significance of latetate accumulattion in blood at altitude. Int. J. Sports Med. 11 (Suppl. 1). S27 $\quad$ S30.

Craig. P.C. 1972. Oxygen uptake at the begimning of work. J. Appl. Physiol. 33.611 615.

di Prampero. P.E.. Matratriat. R.. 1968. Relationship between O. consumption. high energy phosphates and the kineties of $\mathrm{O}_{2}$ debt in exercise. Pllüg. Arch. 3(04. 11 19.

di Prampero. P.F.. Davies. C.T.M.. Cerretelli. P.. 1970. An analysis of $O$, debt contracted in submaximal exerciss. I. Appl. Physiol. 29. 547551

di Prampero. P.F.. Peeters. L.. Margaria. R.. 1973. Alactic () debl and lactic acid production alter exhatusting exercise in man. J. Appl. Physiol. 34. $628 \quad 6.32$.

di Prampero. P.E.. Meyer. M.. Cerretelli. P.. Piiper, J.. 1978a Energetics of anacrobic glycolysis in dog gastrocnemius. Pflüg. Arch. 377. 18.

di Prampero. P.E.. Pendergast. D.R.. Wilson. D.W.. Rennie. D.W. 1978b. Blood lactic acid concentrations in high velocity swimming. In: Eriksson. B.. Furberg. B. (Eds.). Swimming Medicine IV. University Park Press. Baltimore. pp. 249261

di Prampero. P.E.. 1981. Energetics of muscular exercise. Rer Phisiol. Biochem. Pharmacol. 89. 143 222.

di Prampero. P.F... Boutellier. U.. Pietsch. P.. 1983. Oxygen deficit and stores at the onset of muscular exercise in humans. J. Appl. Physiol. 55. $146 \quad 153$.

di Prampero. P.E.. Fusi. S.. Antonutto. G.. 1998. Il concetto di soglia anacrobica: un analisi critica. Med. Sport Turin 51.393400

Fggleton. P.. Eggleton. G.P.. 1927. The inorganic phosphate and a labile form of organic phosphate in the gastrocnemius of the dog. Biochem. J. 21. 190 195.

Ferretti. G.. Gussoni. M.. di Prampero, P.F... Cerretelli. P.. 1987. Fffects of exercise on maximal instantaneous muscular power of humans. J. Appl. Physiol. 62. 2288 .2294.

Fiske. C.H.. Subbarow. Y.. 1927. The nature of inorganic phosphate in the voluntary muscle. Science 65.40) 4(0)3.

Gisolfi. F.. Robinson. S.. Turrell. E.S.. 1966. Effects of aerobic work performed during recovery from exhausting work. I. Appl. Physiol. 21. 17671772.

Grassi. B.. Ferretti. G.. Kayser. B.. Marzorati. M.. Colombini. A.. Marconi. C.. Cerretelli. P.. 1995. Maximal rate of blood lactate accumulation during exercise at altitude in humans. J. Appl. Physiol. 79. 331 3.39.

Henry, F.M. 1951. Acrobic oxygen consumption and alactic debt in musculat work. J. Appl. Physiol. 3. 427 - 438.

Hermansen. L.. 1971. Lactate production during exercise. In: Pernow. B. Saltin. B (Eds.). Muscle Metabolism During Exercise. Plenum. New York. pp. 401407 
Hermansen. L.. Stenswold. I.. 1972. Production and removal of lactale during exercise in man. Acta Physiol. Scand. 86. 191201.

Hill. A.V.. 1924. Muscular activity and carbohydrate metabolism. Science 60. 505514.

Hill. A.V.. 1932. The revolution in muscle physiology. Physiol. Rev. 12. $56 \quad 67$

Juel. C.. 1997. Lactate-proton co-transport in skeletal muscle Physiol. Rev. 77, 321 358.

Kayser. B.. Ferretti. G.. Grassi. B.. Binzoni. T.. Cerretelli. P. 1994. Maximal lateric capacity at altitude: alfect of bicarbonate loading. J. Appl. Physiol. 75. 1070 1074.

Lohmann. K.. 1928, ber die Isolierung verschiedener natülicher Phosphorsäureverbindungen und die Frage ihrer Finheitlichkeit. Biochem. Z. 194. 306327.

Margaria. R.. Edwards. H.T.. Dill. D.B.. 1933. The possible mechanism of contrating and paying the oxygen debt and the role of lactic acid in muscular contraction. Am. J. Physiol. 106, 689 714

Margatria, R. Cerretelli. P.. Aghemo. P.. Sassi, G.. 1963 a. Energy cost of running. J. Appl. Physiol. 18, $367 \quad 370$.

Margaria. R. Cerretelli. P.. di Prampero. P.F.. Massari. C.. Torelli. G., 1963b. Kinetics and mechanism of oxygen debt contraction in man. J. Appl. Physiol. 18. 371377.

Margaria. R.. Cerretelli. P.. Mangili. F.. 1964. Balanee and kinetics of anaerobic energy release during strenuous exercise in man. J. Appl. Physiol. 19.623 628.
Margaria. R.. Aghemo, P.. Sassi. G.. 1971. Lactic acid production in supramaximal exercise. Pflüg. Arch. 326. 152. 161.

Margaria. R.. Camporesi. E.. Aghemo. P.. Sassi, G., 1972. Tho elfect of $O$, breathing on maximal aterobic power. Pflüg. Arch. 336. 225235.

Needham. D.M.. 1971. Machina Carnis. Cambridge University Press. Cambridge

Osnes. J.B.. Hermansen. L.. 1972. Acid base balance after maximal exercise of short duration. J. Appl. Physiol. 32 5963.

Pendergast. D.R.. di Prampero, P.E.. Craig. A.B., Rennie. D.W.. Wilson. D.W.. 1977. Quantitative analysis of the front crawl in men and women. I. Appl. Physiol. 43. 474479 .

Piiper, J., di Prampero. P.E.. Cerretelli. P.. 1968. Oxygen debt and high energy phosphates in the gastrocnemius muscle of the dog. Am. J. Physiol. 215.523 531.

Piiper. J.. di Prampero. P.E.. Cerretelli. P.. 1969. Oxygen consumption and mechanical perlormance of dog gastrocnemius muscle with artificially increased blood flow. Pflüg. Arch. 311.312 325.

Roos. A.. 1975. Intracellular pH and distribution of weak acids across cell membranes. A study of p- and L-lactate and of DMO in rat diaphragm. I. Physiol. London 249. 125. 